shows a peripheral disposition and may protrude from the surface, possibly interacting with other cellular components or with neighbouring neurofilaments. The results presented here indicate that the function performed by the $200 \mathrm{~K}$ protein is not rigidly required by every neurofilament, and is not needed at all stages of development. It should be possible to correlate the presence and absence of this protein with morphological and physiological attributes of particular neurones, and so elucidate the role of this protein in neuronal dynamics.

We thank E. Debus for providing monoclonal antibody to the $200 \mathrm{~K}$ neurofilament protein. G. S. was supported by a postdoctoral fellowship from the Max Planck Society.

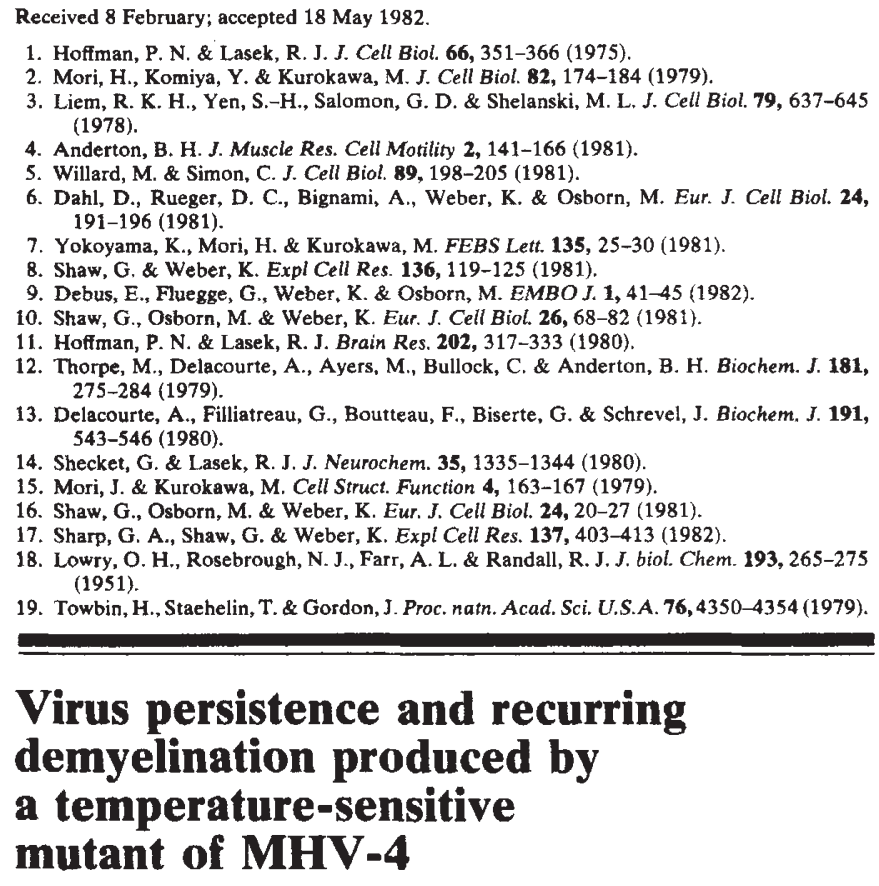

\section{Virus persistence and recurring demyelination produced by a temperature-sensitive mutant of MHV-4}

\author{
Robert L. Knobler*†, Peter W. Lampert $\dagger$ \\ \& Michael B. A. Oldstone* \\ * Department of Immunopathology, Scripps Clinic and Research \\ Foundation, La Jolla, California 92037, USA \\ † Department of Pathology, UCSD School of Medicine, La Jolla, \\ California 92093, USA
}

Mouse hepatitis virus type 4 (MHV-4, the JHM strain), a positive-strand RNA virus of the coronavirus family, is well documented as an inducer of acute ${ }^{1-4}$ and chronic ${ }^{5,6}$ demyelination in mice, as well as subacute demyelination in rats ${ }^{7,8}$, due to a cytolytic infection of oligodendrocytes ${ }^{3,4,7}$. However, experiments to explore the role of virus and host factors in the production of chronic or recurrent demyelinating disease have been limited because MHV-4 usually produces demyelination in conditions that frequently induce a fatal necrotizing encephalomyelitis ${ }^{1-9}$. To circumvent this problem, we had made and selected mutant viruses that caused both a high incidence of demyelination and a low incidence of encephalitis-induced mortality ${ }^{9}$. One such mutant, designated ts8, consistently caused acute demyelinating disease in over $90 \%$ of intracerebrally or intranasally (natural route of infection) inoculated, 4-5 weekold mice from several susceptible strains within 6-10 days ${ }^{9,10}$. In addition, ts8 typically did not cause fatal necrotizing encephalitis, showing a low mortality $(<5 \%)^{9,10}$. This reflected a unique tropism of ts8 for oligodendrocytes, but a limited one for neuronal cells ${ }^{11}$. We now report that ts8 is also useful for inducing persistent infection of the mouse central nervous system (CNS). The histopathological correlate of this infection is chronic recurrent demyelination, and virus can be demonstrated ultrastructurally in intact oligodendrocytes, in the vicinity of demyelinated areas.
$\mathrm{BALB} / \mathrm{c}$ mice, 4-5 weeks old, were inoculated intracerebrally with $10^{4}$ plaque-forming units (PFU) of ts 8 . Tissue homogenates from one group of mice were prepared for virus titration as $10 \% \mathrm{w} / \mathrm{v}$ suspensions ${ }^{12}$. An identically treated group was killed at various time points by intracardiac perfusion with a paraformaldehyde-glutaraldehyde fixative ${ }^{11}$. CNS tissue was embedded in Epon, and sections were stained with uranyl acetate and viewed with a Zeiss EM10 electron microscope ${ }^{11}$. Figure 1 shows the amounts of virus found in brains of animals (five each) at 2, 4, 7, 10, 28, 60 and 365 days after inoculation. Although virus titres had declined by the seventh day after inoculation, brains from three of five mice studied at 365 days after inoculation still yielded infectious virus. Corresponding results were recorded for spinal cord tissues. All animals (25 mice) examined histopathologically 7 days after infection and later, had some degree of demyelination. Virus isolated from animals killed $1 \mathrm{yr}$ after inoculation retained the temperaturesensitive growth characteristics of the initial inoculum. For example, assay of one such sample yielded $1 \times 10^{4} \mathrm{PFU}$ per $\mathrm{g}$ brain at $34^{\circ} \mathrm{C}, 6 \times 10^{3} \mathrm{PFU}$ per $\mathrm{g}$ at $37^{\circ} \mathrm{C}$ and $<10 \mathrm{PFU}$ per $\mathrm{g}$ brain at $39.5^{\circ} \mathrm{C}$. This sample is representative of all three isolates.

The maximal degree of acute demyelination usually corresponded directly to the amounts of infectious virus carried and

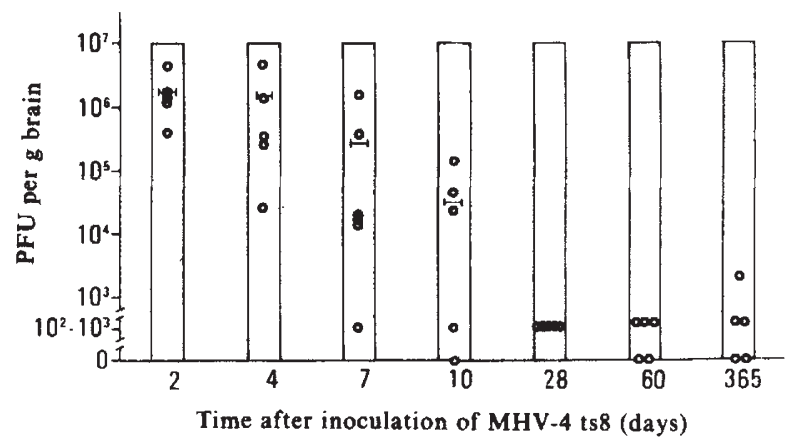

Fig. 1 Virus titres following intracerebral inoculation of $10^{4} \mathrm{PFU}$ MHV -4 ts 8 on day 0 , are expressed as PFU per $g$ of brain tissue. Less than $10 \mathrm{PFU}$ per $\mathrm{g}$ is indicated as zero. Brain homogenates were prepared as a $10 \%$ suspension $(w / v)$ from each animal killed $^{12}$. Five animals were assayed at each time point at $37^{\circ} \mathrm{C}$ and the bar indicates the mean virus titre. A decline in virus titre became evident 7 days after infection and reached a plateau, evident 28 days and thereafter. Virus was isolated from only three

of five animals at both 60 days and 365 days after infection.

was associated with infiltrating inflammatory cells. Remyelination, characterized by thin myelin sheaths around large axonal profiles, was evident at 28 days post-infection (Fig. 2a). Thereafter, recurrent demyelination in areas that had undergone remyelination was found at 57 days (Fig. $2 b$ ) and later. The chronic demyelinating lesion was not usually associated with perivascular cellular infiltrates, although acute demyelination was associated with infiltrating inflammatory cells.

Recurrent demyelination, usually occurring in small foci, was evident at 365 days (Fig. $2 c, d$ ). Virions could be demonstrated ultrastructurally in the cytoplasm of oligodendrocytes located near sites of demyelination $1 \mathrm{yr}$ after inoculation (Fig. $2 e$; this photomicrograph is characteristic of coronavirus virions found in the cytoplasm of several different oligodendrocytes).

Thus, this MHV-4 mutant establishes a reproducible persistent infection in mice and induces a progression from acute demyelinating disease, to a chronic recurring form. The reproducibility of this model now allows a detailed study of virus, host and genetic factors affecting virus persistence and replication in oligodendrocytes, remyelination and recurrent demyelination. 


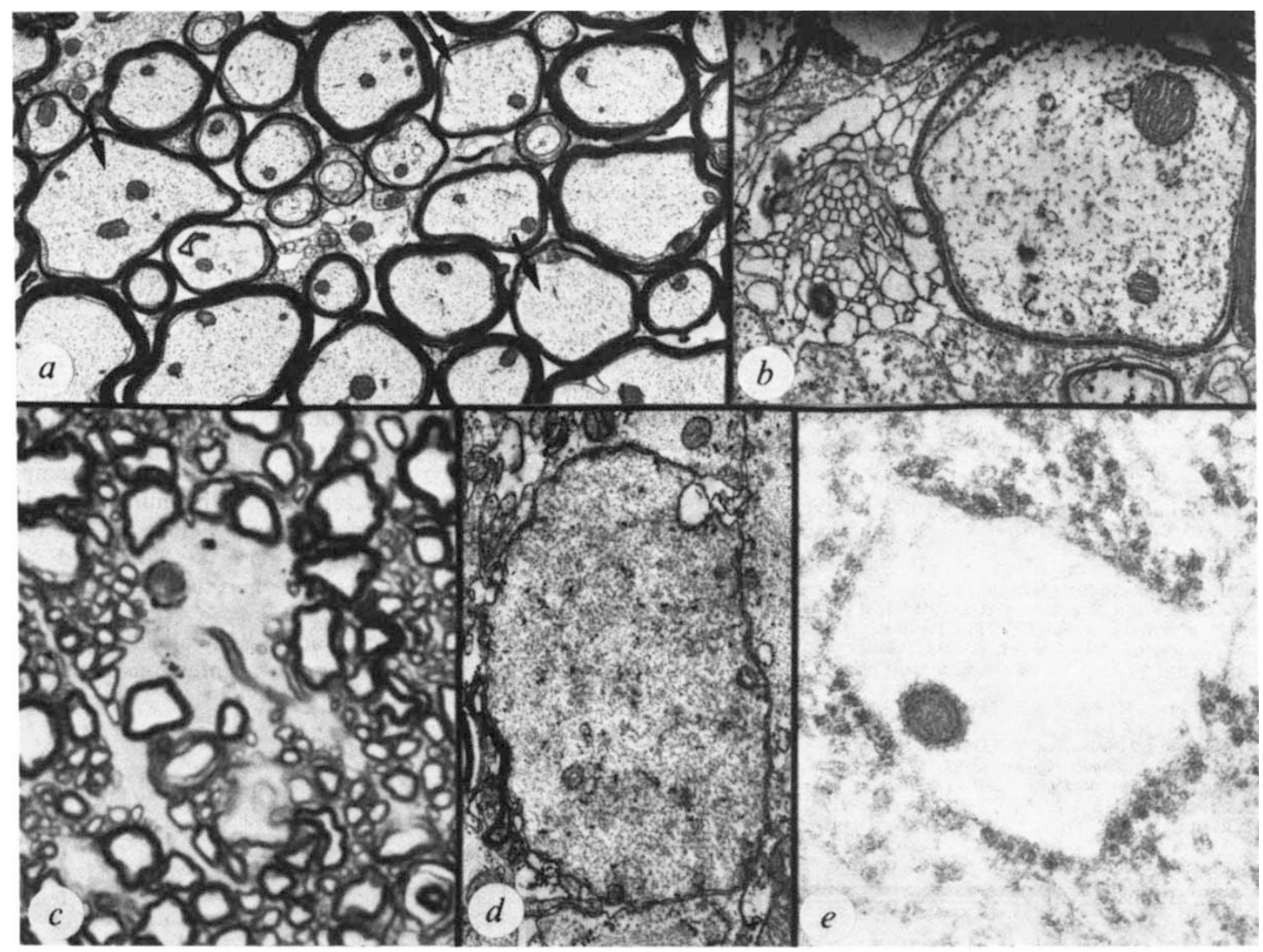

Fig. 2 a, Remyelinated axons were evident at 28 days after infection. They are characterized by thin myelin sheaths around large axonal profiles (see arrows). $\times 5,760 . b$, Recurrent demyelination is evident on an axon previously remyelinated (thin myelin sheath around a large axonal profile) shown at 57 days after infection. $\times 14,400 . c$, A small focus of demyelination surrounded by intact myelinated axons is shown in a portion of the lateral column of the spinal cord at 365 days after infection. $\times 576 . d$, An example of a completely demyelinated axon at 365 days after infection. $\times 14,400$. e, An MHV virion, with its characteristic corona, is demonstrated within a cytoplasmic vacuole, in an oligodendrocyte located near demyelinated axons at 365 days after infection. $\times 108,000$.

The aetiology and pathogenic mechanism(s) of injury in multiple sclerosis, the most common demyelinating disease of man, is unknown. A large body of epidemiological and experimental evidence suggests that this disorder is due to an autoimmune and/or viral disorder ${ }^{13}$. The availability of the ts 8 model should help to further our understanding of the pathogenic mechanism and genetic control of virus-induced acute and recurrent demyelination.

We thank Linda A. Tunison and Robert Garrett for technical assistance and Susan Edwards for manuscript preparation. This work was supported by USPHS grants NS 12428 and NS 14068 . R.L.K. is a recipient of a postdoctoral fellowship from the National Multiple Sclerosis Society.

\footnotetext{
1. Bailey, O. T., Pappenheimer, A. M., Cheever, F. S. \& Daniels, J. B. J. exp. Med. 90, 195-212 (1949)

2. Waksman, B. H. \& Adams, R. D. J. Neuropath. exp. Neurol. 21, 491-518 (1962).

3. Lampert, P. W., Sims, J. K. \& Kniazeff, A. J. Acta Neuropath. 24, 76-85 (1973).

4. Weiner, L. P. Archs Neurol. 28, 298-303 (1973)

5. Herndon, R. M., Griffin, D. E., McCormick, V. \& Weiner, L. P. Archs Neurol. 32, 32-35 (1975).

6. Stohlman, S. A. \& Weiner, L. P. Neurology 31, 38-44 (1981)

7. Nagashima, K., Wege, H., Meyermann, R. \& ter Meulen, V. Acta neuropath. 44, 63-70 (1978).

8. Sorensen, O., Perry, D. \& Dales, S. Archs Neurol 37, 478-484 (1980)

9. Haspel, M. V., Lampert, P. W. \& OJdstone, M. B. A. Proc. natn. Acad. Sci. U.S.A. 75, 4033-4036 (1978)

10. Lampert, P. W., Haspel, M. V. \& Oldstone, M. B. A. in Progress in Multiple Sclerosis Research (eds Bauer, H. J., Poser, S. \& Ritter, G.) 35-39 (Springer, Berlin, 1980)

11. Knobler, R. L. et al. J. Neuroimmun. 1, 81-92 (1981).

12. Knobler, R. L., Haspei, M. V. \& Oddstone, M. B. A. J. exp. Med. 153, 832-843 (1981).

13. Maugh, T. H. II, Science 195, 667-669, 768-771, 969-971 (1977).
}

\section{Donor origin of the in vitro haematopoietic microenvironment after marrow transplantation in man}

\author{
Armand Keating*, Jack W. Singer*, Paul D. Killen†, \\ Gary E. Striker $\dagger$, Armi C. Salo $\dagger$, Jean Sanders $\ddagger$, \\ E. Donnall Thomasł, David Thorning $\dagger$ \\ \& Philip J. Fialkow $\dagger$
}

\begin{abstract}
* The Medical Service, Veterans Administration Medical Center Division of Oncology, 4435 Beacon Avenue South, Seattle, Washington 98108 , USA

$\dagger$ Divisions of Oncology and Medical Genetics, Department of Medicine and Department of Pathology, University of Washington, Seattle, Washington 98195 , USA

¥ Fred Hutchinson Cancer Research Center, Seattle,

Washington 98104 , USA
\end{abstract}

The method for long-term culture of marrow cells in vitro as described by Dexter ${ }^{1}$ has recently been successfully applied to human marrow ${ }^{2,3}$ and is dependent on the development of an adherent stromal cell layer consisting of cells described as "endothelial-like cells, fat cells, and macrophages"4. The present study was designed to determine the origin and composition of the stromal cells forming the in vitro 'microenvironment' and maintaining haematopoeisis in long-term cultures grown from marrows of 14 patients who received marrow 